\title{
COMBATE À EXCLUSÃO E LUTA PELA CIDADANIA: UMA SUPERAÇÃO DO CONCEITO DE EXPLORAÇÃO?
}

\author{
ANA CLAUDIA FARRANHA ${ }^{1}$
}

A presente comunicação tem por finalidade levantar alguns apontamentos preliminares acerca da noção de exclusão e da noção de exploração. Nossa questão central é examinar, através de algumas leituras recentes da teoria social, de que maneira alguns autores vêm privilegiando a noção de exclusão em detrimento da noção de exploração, sob o argumento de que a primeira seria mais abrangente do que a segunda. Estaria a exploração sendo superada pela exclusão social? É possível falar que a luta pela cidadania torna-se central neste contexto?

O fundamento desta problemática se justifica na medida em que observamos um crescente emprego da noção de exclusão para explicar não só o aumento da pobreza, mas também do desemprego e a diversificação dos tipos de ocupação no interior do processo produtivo. Para os autores que privilegiam o uso do conceito, estamos diante de uma nova questão social ${ }^{2}$,

${ }^{1}$ Doutoranda em Ciências Sociais pelo Instituto de Filosofia e Ciências Humanas (IFCH), na Universidade Estadual de Campinas (UNICAMP).

${ }^{2}$ Castel define como nova questão social aquela que se coloca "quando uma sociedade experimenta o enigma de sua coesão e tenta conjurar o risco de sua fratura. $\ddot{E}$ um desafio que interroga, põe em questão a capacidade de uma sociedade...para existir como um conjunto ligado por relações de interdependência”. Neste caso, da mesma maneira que na Primeira Revolução Industrial a questão social relacionava-se com o pauperismo, no contexto atual, as causas da erosão residem na desconstrução do Estado- 
cuja resolução passa fundamentalmente pela diminuição da exclusão social, materializada na luta pela cidadania.

Nosso esforço consistirá em desafiar esta tese e apontar, de maneira preliminar, que a noção de exploração continua válida, tendo em vista que o crescente contingente de homens e mulheres que parece estar à margem do mercado constitui uma peça fundamental da engrenagem que move o capitalismo deste início de século.

Em seguida, apresentaremos os limites que são intrínsecos ao conceito de exclusão e, por fim, problematizaremos os discursos que se ancoram no combate à exclusão como aspecto fundamental para a ampliação da cidadania.

\section{Elementos da noção de exclusão}

Situando os aspectos do tema, é importante notar que os processos de ajuste econômico-financeiro, principalmente na América Latina, desencadearam um conjunto de discussões acerca do que fazer com a massa de trabalhadores que paulatinamente vem sendo expulsa do mercado de trabalho. Neste sentido, um dos debates que vem ganhado maior relevo tem sido o que busca apontar um conjunto de políticas que tem por finalidade combater a exclusão social. Pelo menos três posições diferentes vão tentar explicar a noção de exclusão.

Uma primeira, gestada no interior dos organismos multilaterais, olha para o contexto atual, percebe que uma das consequiências do ajuste foi o aumento da pobreza, principalmente nas camadas onde se verificam índices de extrema pobreza. Entretanto, as soluções apresentadas para a resolução da exclusão restringem-se ao mercado. Em outras palavras, trata-se de minorar as situações de extrema pobreza através de políticas focalizadas. Para aqueles que foram expulsos do mercado de trabalho por força dos processos de reestruturação produtiva, a perspectiva que se coloca faz referência ao desenvol-

Providência, bem como das políticas de integração relacionadas ao modelo fordista de produção e consumo. Robert Castel, As Metamorfoses da Questão Social. Vozes: Rio de Janeiro, 1998, p. 30. 
vimento de um capital humano, capaz de gerar um conjunto de oportunidades que proporcionem a volta dos indivíduos ao mercado de trabalho.

É neste discurso que termos como empregabilidade ganham força e forma. Verifica-se que, por mais que se considerem as conseqüências perversas dos processos de ajuste, a noção de exclusão que se privilegia continua restrita às soluções que o próprio mercado pode produzir, e o conteúdo programático deste discurso passa a ser muito semelhante ao discurso liberal do século XIX. Para os pobres - incapazes de se mover no mercado - destina-se a assistência mais imediata do Estado, assistência compreendida como um ato de benevolência e não como uma política social. Para os que ainda tem alguma possibilidade de inserção no mercado, a reinserção se dará a partir do desenvolvimento das capacidades individuais ${ }^{3}$. Resta saber até quando se é excluído em potencial e quando se torna excluído efetivamente.

Uma outra leitura do conceito de exclusão pode ser explorada num texto de Sônia Fleury ${ }^{4}$ que busca compreender os aspectos deste debate na atualidade. A autora toma a noção de exclusão social numa perspectiva que vai além das questões econômicas. Busca, assim, pensar o conceito a partir da perspectiva de autores como Foucault, Frantz Fannon, Boaventura de Souza Santos e Hannah Arendt, buscando recolocar o tema da diferença no interior do conceito. $\mathrm{O}$ grande mote da discussão passa a ser a possibilidade de aceitar e incorporar o outro nas comunidades políticas ${ }^{5}$. Com esta pers-

\footnotetext{
${ }^{3}$ Algumas formulações acerca desta perspectiva podem ser identificadas no livro organizado por Bernardo Kliksberg, Pobreza: uma questão inadiável - novas propostas a nível mundial. Brasília: ENAP, 1994.

${ }^{4}$ Sônia Fleury, "Política Social, exclusión y equidad en América Latina en los 90". In: Revista Nueva Sociedad, no. 156, julho/agosto 1998.

${ }^{5}$ Lançando mão da discussão apresentada por Boaventura, a autora reproduz as seguintes afirmações do autor:

"Si Marx es el gran teórico de la desigualdad, Foucault es el gran teórico de la exclusion. Si la desigualdad es un fenómemo socioeconomico, la exclusion es, sobre todo, un fenomeno cultural y social, un fenómeno de civilización. Se trata de un proceso histórico a través del cual una cultura, por vía de un discuso de verdad, crea la interdicción y la recaza... El sistema de la desigualdad se asienta, paradójicamente, en el caráter esencial de la igualdad; el sistema de la exclusión se

32 COMBATE À EXCLUSÃO E LUTA PELA CIDADANIA: UMA SUPERAÇÃO DO CONCEITO...
} 
pectiva, identifica exclusão social com a privação ou a negação da condição humana. Compreendendo que o tema exclusão se articula para além das desigualdades sociais e remonta a elementos atinentes ao pertencer, ao agir, e ao reconhecimento de sujeitos políticos, Fleury, apresenta sua definição de exclusão da seguinte forma:

“...la exclusion es un proceso cultural que implica el estabelecimiento de una norma que prohíbe la inclusión de indivíduos, grupos y poblaciones en una comunidad sociopolítica ${ }^{6}$.

A autora assinala, então, que as implicações deste processo redesenhariam aspectos da luta política, a qual passa a ser referenciada na construção de novos sujeitos sociais, na criação de novos direitos de cidadania e em políticas públicas articuladas a partir da idéia de co-gestão ${ }^{7}$.

Existe nesta perspectiva uma identificação com as teses que se referem ao fim da sociedade do trabalho ${ }^{8}$, as quais assinalam uma superação da luta de classes pela luta por cidadania. Parte deste ideário pode ser sintetizado na perspectiva de que a racionalidade produtivista não é mais capaz de promover ao mesmo tempo a integração funcional e a integração social. $\mathrm{Na}$ esfera do trabalho, os indivíduos perdem o vínculo com elementos que se relacionam com as mais diversas esferas da vida, o que tem como conseqüência imediata a perda de identidade de classe 9 .

Gorz identifica esta inexistência de condições para uma ação classista no fato de que há um contingente cada vez maior de indivíduos que se encontram à margem do mercado de trabalho formal e, assinala que há uma crescente diferenciação no interior da classe trabalhadora, o que levaria à

asienta en el carácter esencial de la diferencia... El grado extremo de la exclusión es el exterminio; el grado extremo de la desigualdad es la esclavitud." Boaventura de Souza Santos, A Construção Multicultural da Igualdade e da Diferença, VII Congresso Brasileiro de Sociologia, Rio de Janeiro, 1995, p. 2-4.

${ }^{6}$ Fleury, op. cit., p. 83.

${ }^{7}$ Idem, p. 84.

${ }^{8}$ Pode-se citar as idéias de Gorz, Offe e Habermas.

${ }^{9}$ André Gorz, Adeus ao Proletariado. Rio de Janeiro: Forense Universitária, 1982, p. 86. 
emergência de uma identidade classista. Todo este processo é caracterizado como o nascimento de uma classe dos não trabalhadores. A existência de um contigente cada vez maior de pessoas sem trabalho passa a ser determinante para que se declare o fim do trabalho e se construam políticas sociais que buscam combater a exclusão ${ }^{10}$, sem contudo considerar que o cerne da exclusão ainda reside na exploração capitalista.

\section{Retomando a noção de exclusão: a exclusão como irmã-caçula da exploração?}

Como afirmamos no início desta comunicação, pode-se identificar, pelo menos, três posições acerca da noção de exclusão. Uma primeira referenciada na posição liberal: capacita-se o indivíduo e ele está apto a não estar fora do mercado. Uma segunda que se esvazia do elemento atinente às desigualdades sociais e recoloca o debate sob o patamar da política, apontando que o desafio neste caso se refere à constituição de parâmetros, normas e consensos que ampliem o reconhecimento da alteridade e da diferença.

Uma terceira posição se propõe a ver os nexos constitutivos entre esta noção e a de exploração. Para tanto, tomamos como ponto de referência uma definição de exclusão social em que

"El tema de la "exclusión social" asume la forma del estudio de los mecanismos de expulsión de las relaciones formales de trabajo, de las nuevas supervivencia de los nichos de economía informal, de las nuevas formas de sociabilidad possibles y de los nuevos valores que ellas puedem engendar"11.

Ora, se se trata de compreender exclusão social a partir das alterações no interior do processo produtivo, cabe, então, fornecer uma outra ex-

${ }^{10}$ Pode-se citar dentre estas políticas as de renda mínima, que passam a ser desvinculadas da noção de trabalho para ligar-se à perspectiva de cidadania. Sobre isto ver: Josué Pereira da Silva, Alienacion, Work and Utopia: A study of thee thought of André Gorz. (Tese de Doutorado), 1993, New School for Social Research, e Renda Mínima, Trabalho e Cidadania: Projeto Suplicy em Debate, Estudos Economicos, vol. 28, no. 04, 1998.

${ }^{11}$ Emir Sáder, Brasil: una cartografia de la injusticia. Democracia sin exclusiones ni excluidos. Venezuela: Nueva Sociedad, 1998, p. 160.

34 COMBATE À EXCLUSÃO E LUTA PELA CIDADANIA: UMA SUPERAÇ̃̃O DO CONCEITO... 
plicação ao que Gorz chama de classe dos não trabalhadores e observar como o crescente desemprego mostra uma outra face do capitalismo, em que os homens parecem ser supérfluos. Tosel ${ }^{12}$ aponta para um movimento altamente paradoxal no interior do capitalismo, pois

"se cada trabalhador assalariado aciona cada vez mais trabalho acumulado, em valor e em capacidade técnica, o emprego não pode continuar a crescer porque o crescimento econômico exige a introdução cada vez mais veloz da inovação tecnológica produtora do lucro"13.

Sendo assim, não resta dúvida de que há uma diminuição do emprego à medida que ocorre o desenvolvimento tecnológico, entretanto, isto não significa que o trabalho vivo estaria sendo substituído pelo tempo do não trabalho, de um tempo livre, capaz de proporcionar um conjunto de atividades, as quais Marx denomina de reino da liberdade. É exatamente este processo, em que uma aparente não centralidade do trabalho parece substituir o trabalho vivo, que os autores que discutem a exclusão como uma nova forma de conflito social desconsideram a sua vinculação com os elementos da exploração capitalista e passam a ver a luta pela cidadania como a única capaz de promover a emancipação.

Vivemos, assim, sob uma forma de acumulação em que a redução do proletariado estável, a ampliação do trabalho intelectual abstrato no interior das fábricas modernas, a ampliação generalizada das formas de trabalho precarizado denotam aspectos os quais assinalam a continuidade da vigência da lei do valor ${ }^{14}$. A pergunta cabível aqui é: que fase da acumulação capitalista, aparentemente tão diferente dos requerimentos apresentados pela grande indústria, é esta?

${ }^{12}$ Andre Tosel, "Centralité et non-centralité du travail ou la passion des hommes superflus". In: Jacques Bidet e Jacques Texier (dir.), La crise du travail (Actes du colloque organisé par la revue Actuel Marx - PUF, CNRS, Paris X). Paris: PUF, 1995, pp. 210218.

${ }^{13}$ Tosel, op. cit., p. 210, (Tradução da autora).

${ }^{14}$ Ricardo Antunes, "Mundo do Trabalho e Teoria do Valor: as formas vigência do trabalho material e imaterial". In: Os sentidos do trabalho: ensaio sobre a afirmação e a negação do trabalho. São Paulo: Boitempo, 1999, p. 120. 
Teixeira ${ }^{15}$ assinala que se trata de uma fase de acumulação sem desenvolvimento, onde a produção das mercadorias necessitaria cada vez menos da ampliação numérica da força de trabalho, ao mesmo tempo em que carece cada vez mais da sua intensificação, buscando assim a autovalorização. É como se a autonomização deste processo chegasse a um ponto tal que a força de trabalho se constituiria, no que tange à aparência, como supérflua ${ }^{16}$.

Diante destas considerações é que a noção de exclusão merece ser retomada. Para nós, discutir a exclusão social é compreendê-la dentro do processo de acumulação capitalista, em que a existência de contingentes enormes de homens que estão fora não só do mercado de trabalho mas, principalmente, de um processo de socialização capaz de gerar as condições que extrapolam o reino da necessidade e adentram o reino da liberdade, não pode ser tomada como um dado a priori. Neste sentido, parece ser correto afirmar que a noção de exclusão social não pode ser compreendida como uma categoria de análise que se autonomiza e possibilita, assim, um conjunto de propostas políticas baseadas apenas na sua constatação. Antes pelo contrário, discutir propostas de combate à exclusão social é, fundamentalmente, discutir que sua ampliação no contexto atual guarda estreita conexão com o conceito de exploração, o qual merece ser discutido à luz das transformações contemporâneas do capitalismo. Mas aí as soluções que privilegiam unicamente a esfera política certamente não serão cabíveis e o debate se recoloca na perspectiva de alternativas fundadas numa crítica radical à lógica do capital. Em outras palavras, falar em combate à exclusão social só se justifica na medida em que se busca atacar sua raiz: a exploração capitalista.

${ }^{15}$ F. J. S. Teixeira, "O Capital e suas formas de produção de mercadorias: rumo ao fim da economia política". In: A obra teórica de Marx: atualidade, problemas e interpretações. São Paulo : Xamã, 2000.

${ }^{16}$ Aqui vale a pena retomar as considerações de Tosel. Os homens supérfluos seriam justamente aqueles produzidos pela busca absoluta da mais-valia. Afirma assim que

"A busca absoluta da mais-valia produz a condenação ao não-trabalho, como lazer forçado, como compulsão ao desemprego e à inatividade necessária. A necessidade do trabalho necessário não produz a liberdade do trabalho-necessidade e o tempo livre; ela produz a necessidade do apodrecimento do tempo livre como desemprego, ela engendra - não o supérfluo positivo do tempo disponível, mas - a superfluidade negativa dos não-trabalhadores, a figura antropológica negativa do 'homem supérfluo' tornado inútil, do homem a mais”. Tosel, op. cit., p. 216, (Tradução da autora). 